\title{
Correction to: Clinical Outcomes of Ambulatory Endovascular Treatment Using 4-French and 6-French Femoral Access Strategies: The Bio4amb Multicentre Trial
}

\author{
Marianne Brodmann ${ }^{1}$ - Koen Deloose ${ }^{2}$ Eric Steinmetz ${ }^{3}$ Olivier Regnard ${ }^{4}$. \\ Jens C. Ritter $^{5}$ - Ludovic Berger ${ }^{6}$ - Johannes B. Dahm ${ }^{7}$ - Shirley Jansen ${ }^{8,9,10,11}$ • \\ Bibombe P. Mwipatayi ${ }^{12}$ - Pascal Desgranges ${ }^{13} \cdot$ Klaus Hausegger $^{14}$. \\ Jos C. van den Berg ${ }^{15,16}$ on behalf of the BIO4AMB investigators
}

\section{Cardiovasc Intervent Radiol (2020). https://doi.org/10.1007/s00270-020-02738-5}

The original version of this paper did not contain a list of Bio4amb investigators. The purpose of this correction is to acknowledge the contribution of all investigators who participated in the study. The ESM (Electronic

The original article can be found online at https://doi.org/10.1007/ s00270-020-02738-5.

\author{
Marianne Brodmann \\ marianne.brodmann@medunigraz.at \\ Koen Deloose \\ koen.deloose@telenet.be \\ Eric Steinmetz \\ eric.steinmetz@chu-dijon.fr \\ Olivier Regnard \\ olivier.regnard@gmail.com \\ Jens C. Ritter \\ jc.ritter@web.de \\ Ludovic Berger \\ berger-1@chu-caen.fr \\ Johannes B. Dahm \\ dahm@hgz-goettingen.de \\ Shirley Jansen \\ Shirley.Jansen@health.wa.gov.au \\ Bibombe P. Mwipatayi \\ patrice@bibombe.com \\ Pascal Desgranges \\ pascal.desgranges@aphp.fr \\ Klaus Hausegger \\ Klaus.Hausegger@kabeg.at
}

Supplementary Material) file of the original article has been corrected.

Contributors: Bio4amb investigators: Olivier Regnard, Marianne Brodmann, Koen Deloose, Jens Carsten Ritter, Ludovic Berger, Johannes Dahm, Shirley Jansen, Bibombe Patrice Mwipatayi, Joseph Touma, Eric Ducasse, Antoine Millon, Sébastien Veron, Raphael Coscas, Eric Steinmetz, Fabrice Schneider, Lieven Maene, Bahaa Nasr, Gilles Miltgen, Vikram Puttaswamy, Jürgen Torsten Verbist, Jonathan Sobocinski, Armand Bourriez, Mark Jackson,

Jos C. van den Berg

josua.vandenberg@eoc.ch

1 Department of Angiology, Medical University Graz, Auenbruggerplatz 15, 8036 Graz, Austria

2 Department of Vascular Surgery, Sint Blasius Hospital, Dendermonde, AZ, Belgium

3 Department of Cardiovascular and Thoracic Surgery, CHU François Mitterrand, Dijon, France

4 Department of Vascular Surgery, Clinique Saint Joseph, Trelaze, France

5 Department of Vascular Surgery, Fiona Stanley Hospital, Perth, Australia

6 Vascular Surgery Department, CHU de Caen, France

7 Department of Angiology and Cardiology, Herz- und Gefässzentrum Neu-Bethlehem, Göttingen, Germany

8 Department of Vascular and Endovascular Surgery, Sir Charles Gairdner Hospital, Perth, WA, Australia

9 Curtin Medical School, Curtin University, Bentley, Perth, WA, Australia

10 Heart and Vascular Research Institute, Harry Perkins Institute for Medical Research, Perth, WA, Australia 
Laurent Casbas, Didier Paneau, Isabelle Bayens, Klaus Hausegger, David Lambrechts, Adrien Kaladji, Flemming Randsbaek, Pierre Jules Delannoy, Manfred Spanger, Jos C. van den Berg.

Open Access This article is licensed under a Creative Commons Attribution 4.0 International License, which permits use, sharing, adaptation, distribution and reproduction in any medium or format, as long as you give appropriate credit to the original author(s) and the source, provide a link to the Creative Commons licence, and indicate if changes were made. The images or other third party material in this article are included in the article's Creative Commons licence, unless indicated otherwise in a credit line to the material. If material is not included in the article's Creative Commons licence and your intended use is not permitted by statutory regulation or exceeds the permitted use, you will need to obtain permission directly from the copyright holder. To view a copy of this licence, visit http://creativecommons. org/licenses/by/4.0/.

Publisher's Note Springer Nature remains neutral with regard to jurisdictional claims in published maps and institutional affiliations.

11 University of Western Australia, Perth, WA, Australia

12 Perth Institute of Vascular Research, Hollywood Specialist Centre, Nedlands, Australia

13 AP-HP, Hopital Henri Mondor, Creteil, France

14 Department of Diagnostic and Interventional Radiology, LKH, Klagenfurt, Austria

15 Centro Vascolare Ticin, Ospedale Regionale Di Lugano, Lugano, Switzerland

16 Universitätsinstitut Für Diagnostische, Interventionelle Und Pädiatrische Radiologie, Universitätsspital Bern, Bern, Switzerland 